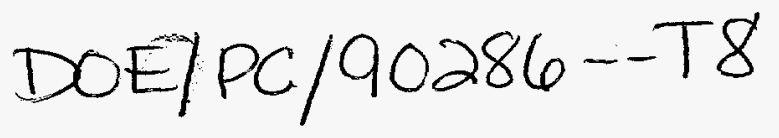

\title{
Combustion Fume Structure and Dynamics
}

CONTRACT NUMBER: DE-FG22-90PC90286

CONTRACTOR: California Institute of Technology, Pasadena, CA 91125

PRINCIPAL INVESTIGATOR: Richard C. Flagan

PETC PROJECT MANAGER: Phillip M. Goldberg

PERIOD OF PERFORMANCE: 8/16/91 - 2/15/92

\section{Introduction}

During pulverized coal combustion, a fume of submicron particles is formed from when mineral that have volatilized from the parent coal nucleate to form new particles. The particles thus generated are extremely small, but they grow rapidly due to Brownian coagulation. Much has been learned about these fine particles in experimental studies of the particles formed in coal combustion. Measurements of the variation of chemical composition with particle size clearly demonstrate that the particles smaller than about $0.1 \mu \mathrm{m}$ in diameter are formed from vapors while larger particles are dominated by residues from the mineral matter in the coal. $[1,2,3]$ Theoretical predictions of the evolution of the particle size distribution suggest that the nuclei should produce a sharp peak which may approach $0.1 \mu \mathrm{m}$, but they are unlikely to grow much beyond that size in the limited time available in practical combustors. Most of the predictions have, however, been based on the dynamics of dense spherical particles. Examination of the fume particles by high resolution electron microscopy reveals that the coal ash fume, like soot particles produced in a broad spectrum of hydrocarbon flames, do not coalesce completely upon coagulation. Instead, the particles grow as low density agglomerates of small, roughly spherical primary particles.

The structures of combustion fume particles have elicited considerable interest since Forrest and Witten [4] observed that the particle structures exhibit dilation symmetry, i.e., the particle structure appears the same when viewed over a range of magnifications. Moreover, the structures are similar for particles from a wide range of sources and materials. These particles have been characterized as fractal or fractal-like, with the mass of the aghloprate varying as a power law of agglomerate size, i.e.

$$
m \propto r^{D}
$$

where $D$ is the fractal dimension. The formation of fractal agglomerates has beenattrituted to agglomeration without coalescence.

The particle structure is important if the deleterious effects of combustion funfes on both the environment and on equipment operation are to be understood. Futrthermore, particle structure is of fundamental importance to the understanding of the dynamics of the fume. Particle growth by coagulation depends upon the mobilities of the particles and on their collision cross sections. The former aspects are relatively well understood as a result of studies performed at Caltech and elsewhere. [5] Experimental measurements have been made to determine the mobility/fractal dimension relationships for particles with the limited range of fractal dimensions that result from cluster-cluster aggregation. The collision cross 


\section{DISCLAIMER}

Portions of this document may be illegible in electronic image products. Images are produced from the best available original document. 
sections of agglomerate particles are less well understood, being much more difficult to attack experimentally.

An important tool in the study of agglomerate particles has been computer simulation. Simulation how the random motions of small particles leads to the formation of low density agglomerates that has revealed the reasons for the structural similarities of particles from different sources. [6] If one assumes that two particles stick rigidly together when they collide, the low density structures observed in combustion fumes are readily reproduced. Relatively dense particles $(D \approx 2.4)$ are produced when individual spheres diffuse to the surface of the growing aggregate. This process has come to be known as diffusion limited aggregation (DLA). Lower density aggregates $(D \approx 1.8)$ result from coagulation of like-sized aggregates, a process known as cluster-cluster aggregation (CCA). The calculations that predict these structures make one critical assumption that is not valid for coal ash fumes, namely that the structures of the aggregates do not change after agglomeration. Some calculations have allowed the primary particles to migrate within the agglomerates, e.g., by rotation, but the integrity of the primary particles is maintained in all these calculations. At the high temperatures of coal combustion, one must also consider the possibility that the particles may sinter together, increasing both the primary particle size and the agglomerate density. This is expected to alter the fractal dimension, although no fundamental studies of these more complicated processes have been reported to date.

The focus of this research program is on elucidating the fundamental processes that determine the particle size distribution, composition, and agglomerate structures of coal ash fumes. The ultimate objective of this work is the dèvelopment and validation of a model for the dynamics of combustion fumes, describing both the evolution of the particle size distribution and the particle morphology. The study employs model systems to address the fundamental questions and to provide rigorous validation of the models to be developed. This first phase of the project has been devoted to the development of a detailed experimental strategy that will allow agglomerates with a broad range of fractal dimensions to be studied in the laboratory.

\section{Agglomerate Structure Characterization}

The determination of the fractal dimension can be made using real-space observations in which the geometry of the aggregate is examined directly, or through the use of scattering techniques. In the initial phase of this research, agglomerate structure measurements were made using image analysis of transmission electron microscope pictures. Although useful information was obtained in this way, the method yields unambiguous results only for particles with fractal dimensions well below two. This is illustrated in Fig. (1 by the comparison between mass and projected area fractal dimensions of computer generated agglomerates.[7] While most fume agglomerates have mass fractal dimensions below 2 , particles with higher fractal dimensions are important in systems in which the particles undergo significant sintering as they grow. Since the coupling of condensed phase rearrangements with agglomeration processes is one of the issues to be addressed in this research program, we require an experimental technique that is applicable to higher fractal dimensions as well.

Scattering of light, $x$-rays, or neutrons can also be used to determine the fractal dimen- 


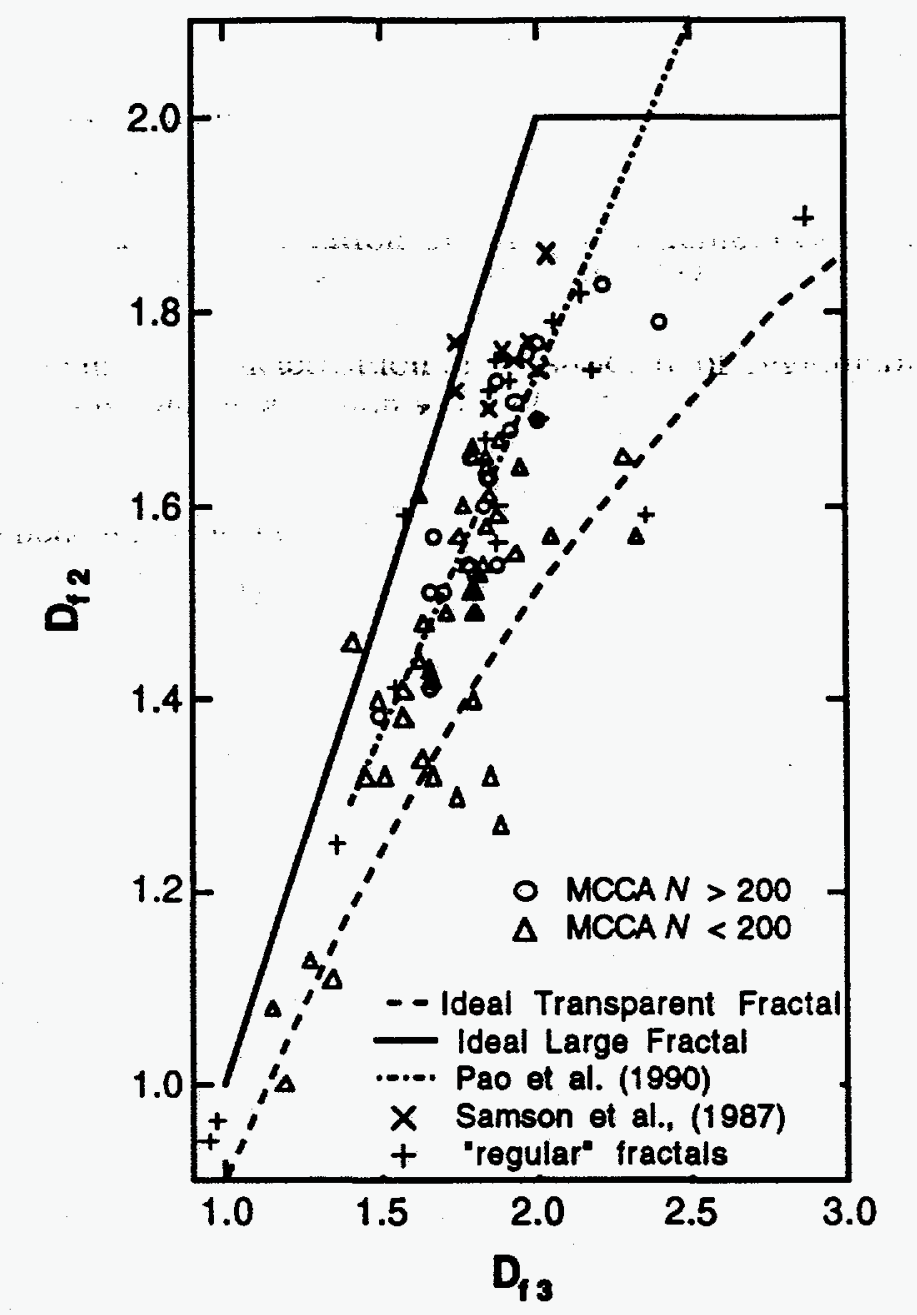

Figure 1: Comparison of mass fractal dimensions $D_{f 3}$ and projected area fractal dimensions $D_{f 2}$ of computer individual, computer-generated agglomerates as measured using the pair correlation functions. The agglomerates were generated using the modified cluster-cluster aggregation (MCCA) algorithm. Results are divided into two cluster size categories in terms of the numbers of primary particles in the aggregate. (From Rogak and Flagan.[]

sion. The range of length scales that can be probed depends upon the wavelength of the radiation being employed and the angular resolution of the experimental apparatus. The range of wavevectors available in light scattering experiments limits optical methods to the measurement of structures larger than about $200 \mathrm{~nm}$. Small angle x-ray scattering (SAXS) can be used to probe smaller scales, but due to the short wavelengths employed and the angular resolution of conventional instruments, SAXS is generally limited to probing scales smaller than $60 \mathrm{~nm}$. Of the methods commonly applied to the fractal characterization of agglomerate particles, only neutron scattering can cover the full range of length scales of interest in a single measurement. Unfortunately, monochromatic neutron sources are not readily available for routine measurements as we will require in our future experiments. SAXS measurements have traditionally been made using pinhole cameras with long optical paths to achieve the angular resolution, and high resolution is achieved only at the expense 
of x-ray intensity in such instruments.

A number of developments have been made in recent years that make SAXS mor readily accessible. The Bonse-Hart multiple reflection diffractometer was developed nearly 3 decades ago, and has been applied in recent years to small angle neutron scattering [8] Coupled to rotating anode sources, the Bonse-Hart system has recently been applied to SAXS measurements in colloidal systems. $[9,10,11]$

A unique instrument with similar capabilities has been developed in the Materials Sciences Department; at Caltech for the measurement of small angle x-ray scattering spectra over a much wider range of structure scales than is accessible in conventional instruments. The instrument, illustrated in Fig. 2 employs two double-bent crystal monochrometers (Johansson crystals) and a linear position sensitive detector to probe structures in the range from 20 to $300 \mathrm{~nm}$. Thus, this new SAXS system bridges the gap between conventional SAXS systems and angular light scattering measurements. The use of focussing $\mathrm{x}$ ray optics provides intensities far greater than those attainable even with the Bonse-Hart apparatus, facilitating SAXS work in the university laboratory rather than requiring national laboratory facilities. The instrument's applicability to structure parameter measurements of fractal agglomerates has been demonstrated by measurements on materials (Cabosil M5, a commercially available fumed silica). that previous investigators have characterized with neutron and other conventional scattering instruments. Figure (3) shows the scattering data obtained for a suspension of the $\mathrm{SiO}_{2}$ particles in water, revealing a mass fractal dimension of 1.8 as previously observed by Martin et al.[12] using small angle x-ray scattering measurements made with a pinhole camera on a rotating anode source to probe momentum transfers in the range above about $0.003 \mathrm{~cm}^{-1}$ (corresponding to length scales from $10 \AA$ to $125 \AA$ ), and light scattering to probe smaller momentum transfer and larger length scales.

\section{Coalescence Kinetics}

Sintering theory has been studied extensively in the ceramics community, although there are some major differences between the problems commonly encountered in the sintering of a ceramic compact and those that must be addressed to describe the simultaneous coalescence and agglomeration of pyrogenic aerosols. One notable difference is the lack of constraints on the rearrangements that can take place as aerosol agglomerates sinter, at least during the early stages of sintering. This contrasts with the highly constrained structures of ceramic compacts. Furthermore, much of the sintering theory has been devoted to the early stages of neck formation, whereas aerosol agglomerates undergo many generations of complete coalescence of adjoining primary particles during sintering. To understand the structural rearrangements of fractal-like agglomerate particles as they sinter requires relatively simple descriptions of the mass transfer between neighboring primary particles, so extensions of the classical descriptions to the later stages of sintering have been developed. An experimental program is now underway to test these models.

The experimental program is based upon model systems that allow precise control of

the aerosol concentrations and properties to promote a fundamental understanding of the dynamics of agglomerate aerosols. By avoiding the complications of heterogeneous coal minerals and the associated property variations and uncertainty in fume source rates, precise 


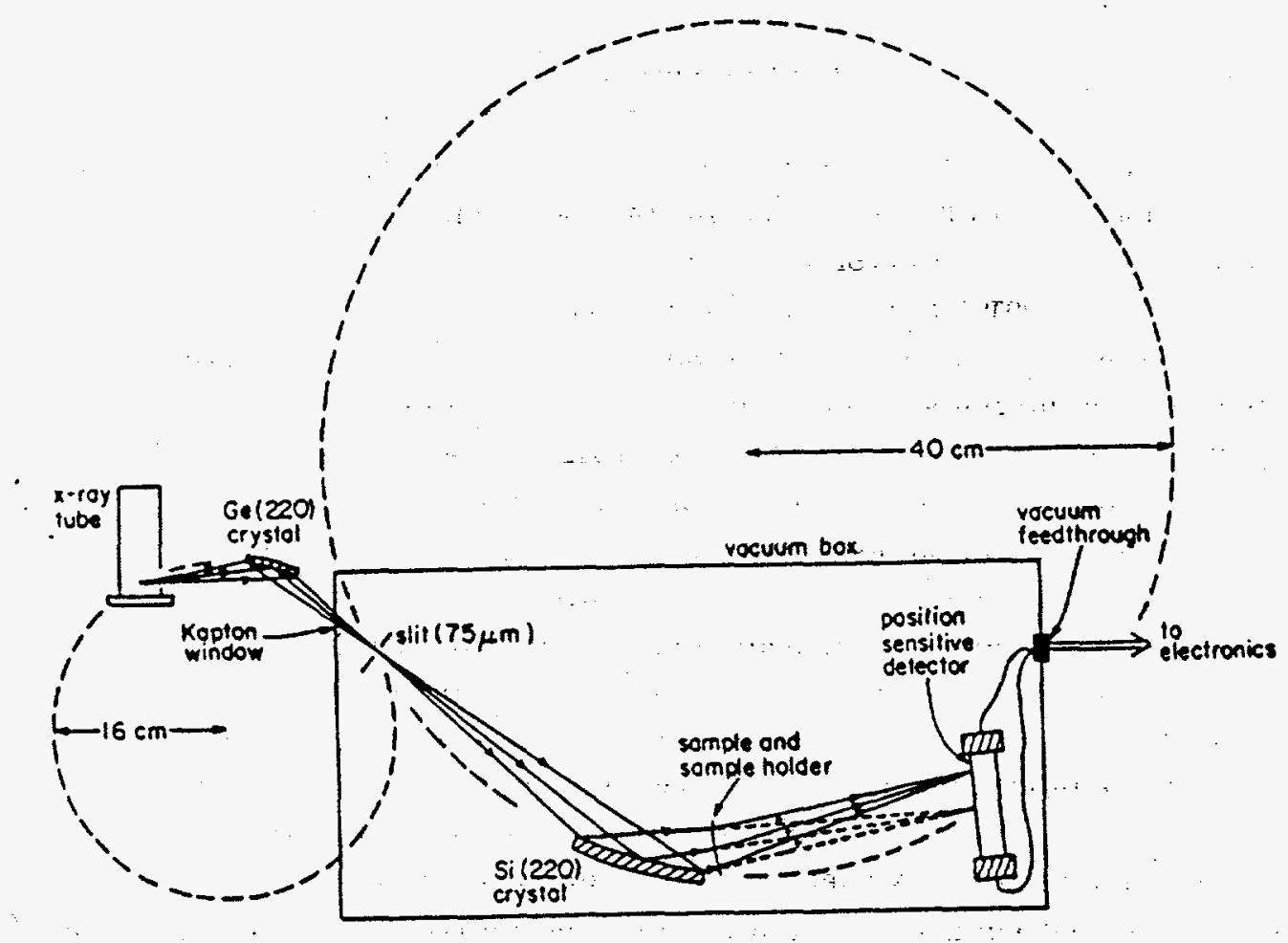

Figure 2: Schematic of the double Johanssen crystal SAXS apparatus developed by Professor William Johnson of the Materials Science Department at Caltech. The focussion optics greatly enhance the intensity. This combined with the use of the position sensitive detector facilitates rapid acquisition of SAXS data using conventional $\mathrm{x}$-ray sources.

measurements of fume evolution becomes possible. Metal alkoxides are being pyrolyzed to produce single component metal oxide fumes. Initial experiments have employed a small reactor to synthesize $\mathrm{TiO}_{2}$ fumes by pyrolysis of titanlum tetraisopropoxide. The aerosols produced in this low residence time reactor will be allowed to agglomerate at room temperature to make coagulation rate measurements. During the start-up phase of this research, The nature of the particles produced by this small reactor have been probed using the scanning electricla mobility spectrometer (SEMS) developed at Caltech by Wang and Flagan. [14]

\section{Agglomeration Rates}

The rate of Brownian coagulation is determined by the collision cross section of a particle and its diffusivity, with corrections required for noncontinuum effects in the particle motion. The theory for particles that coalesce immediately upon collision is well established, but agglomerate particles have received less attention, particularly those in the transition regime. Aerosol agglomerates are produced by coagulation of fine particles produced by homogeneous nucleation. Below some limiting size, the sintering kinetics are such that the agglomerates rapidly coalesce, whereas larger agglomerates coalesce only slowly. Thus, the 


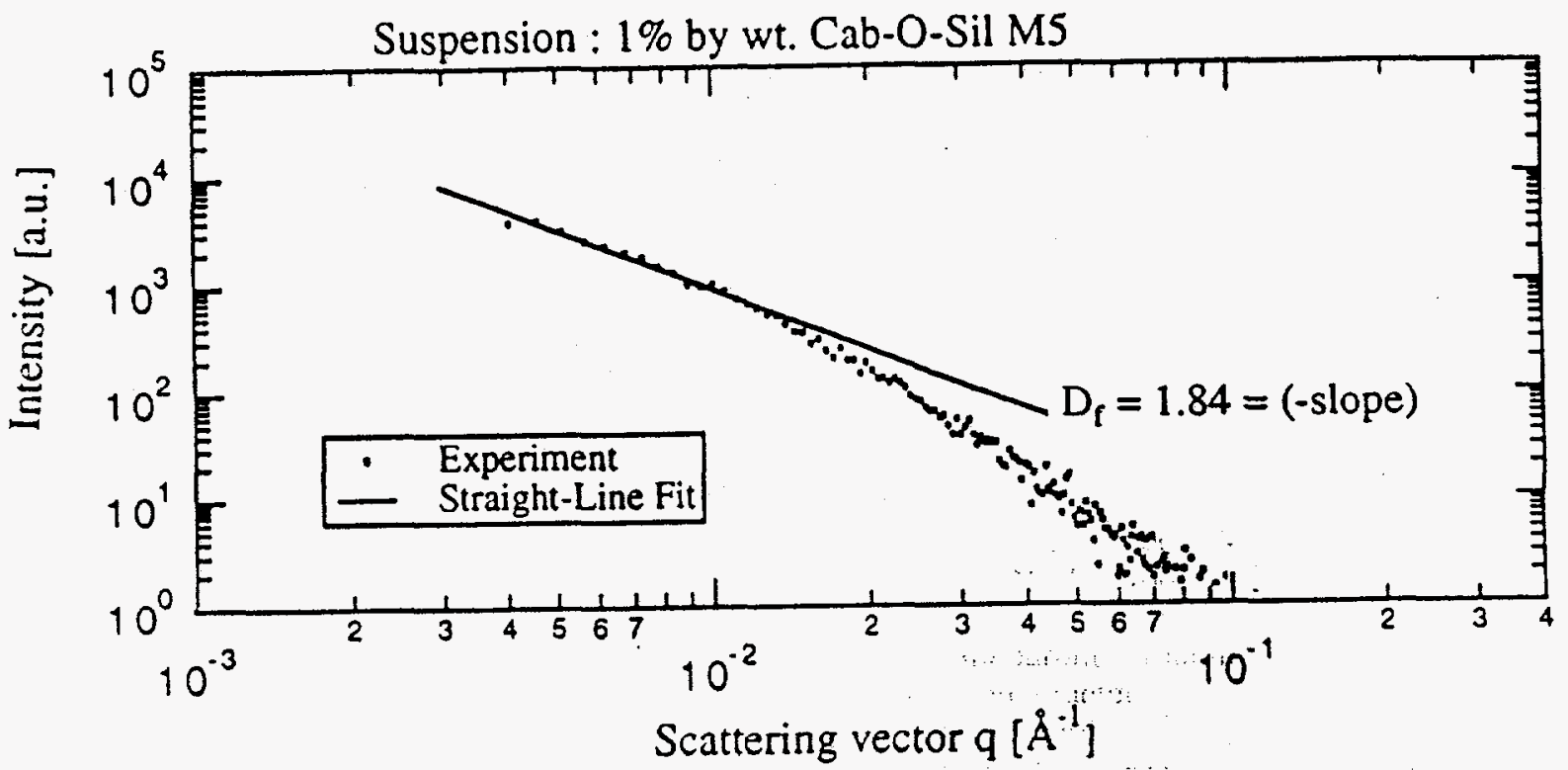

Figure 3: SAXS data obtained using Cabosil M5 in the SAXS apparatus illustrated above. The mass fractal dimension inferred from these data is also given.

physical properties of the particulate material determine the size of the primary particles that ultimately comprise the agglomerates while the collision frequency determines the size to which the agglomerates grow. Using information on the particle structure and mobility, approximate collision frequency functions $K\left(v_{1}, v_{2}\right)$ have been derived. The resulting function $K\left(v_{1}, v_{2}\right)$ was used in a sectional aerosol dynamic code to probe the influence of particle structure on the growth rate of agglomerate particles, and has been described in a paper.[13] Experiments planned for the experimental validation of these predictions have been delayed, but will be conducted within the next year.

\section{References}

[1] D. D. Taylor and R. C. Flagan. Aerosols from a laboratory pulverized coal combustor. In Atmospheric Aerosol: Source/Air Quality Relationships, volume 167, pages 157-172. ACS Symposium Series, 1981.

[2] M. Neville and A. F. Sarofim. The stratified composition of inorganic submicron particles produced during coal combustion. In Nineteenth Symp. (Int.) on Combustion, pages 1441-1449. The Combustion Institute, Pittsburgh, PA, 1982. 
[3] R. J. Quann and A. F. Sarofim. Vaporization of refractory ioxides during pulverized coal combustion. In Nineteenth Symp. (Int.) on Combustion, pages 1429-1440. The Combustion Institute, Pittsburgh, PA, 1982.

[4] S. R. Forrest and T. A. Witten. J. Phys. A.: Math. Gen., 12:L109-L117, 1979.

[5] S. N. Rogak. PhD thesis, California Institute of Technology, Pasadena, CA, 1991.

[6] P. Meakin. On Growth and Form, pages 111-135. 1986.

[7] S. N. Rogak and R. C. Flagan. Characterization of the structure of agglomerate particles. Partice and Particle Systems Characterization, 9:19-27, 1992.

[8] D. W. Schaefer, A. J. Hurd, D. K. Christen, S. Spooner, and J. S. Lin. Growth and structure of pyrogenic silica. In Better Ceramics Through Chemistry III, volume 121, pages 305-310. Materials Research Society Symposium Proceedings, 1988.

[9] A. N. North, J. S. Rigden, and A. R. Mackie. Development of ultrasmall-angle scattering for studies of colloidal systems. Rev. Sci. Instrum., 63:1741-1745, 1992.

[10] H. Matsouka, K. Kakigami, N. Ise, Y. Kobayashi, Y. Machitani, T. Kikuchi, and T. Kato. Ultra-small-angle x-ray-scattering study: preliminary experiments in colloidal suspensions. Proc. Natl. Acad. Sci. USA, 88:6618-6619, 1991.

[11] J. Lambard and T. Zemb. A triple axis bonse hart camera used for high resolution small-angle scattering. J. Appl. Crystallography, 24:555-561, 1991.

[12] J. E. Martin, D. W. Schaeffer, and A. J. Hurd. Fractal geometry of vapor-phase aggregates. Physical Review A, 33:3540-3543, 1986.

[13] S. N. Rogak and R. C. Flagan. Coagulation of aerosol agglomerates in the transition regime. J. Colloid Interface Sci., 151:203-224, 1992.

[14] S. C. Wang and R. C. Flagan. Aerosol Sci. Technol., 13:230, 1990.

\section{DISCLAIMER}

This report was prepared as an account of work sponsored by an agency of the United States Government. Neither the United States Government nor any agency thereof, nor any of their (implied, or assumes any legal liability or responsiemployees, makes any warranty, express or implied, of ass information, apparatus, product, or bility for the accuracy, completeness, or usefulness of any information, apparalus, product, process disclosed, or represents that its use would not infringe privat on name, trademark, ence herein to any specific commercial product, process, or service by trade name, trademark, manufacturer, or otherwise does not necessarily constitute or imply its endorsement, recommendation, or favoring by the United States Government or any agency theref. The of the and opinions of authors expressed herein do not United States Government or any agency thereof. 
Papers originating from this grant are:

S.N. Rogak and R.C. Flagan. "Coagulation of aerosol agglomerates in the transition regime," J. Colloid and Interface Science 151(1), 203-224, 1992.

S.N. Rogak and R.C. Flagman. "Characterization of the structure of agglomerate particles," Particle and Particle Systems Characterization 9, 19-27, 1992.

Copies of these two papers are enclosed.

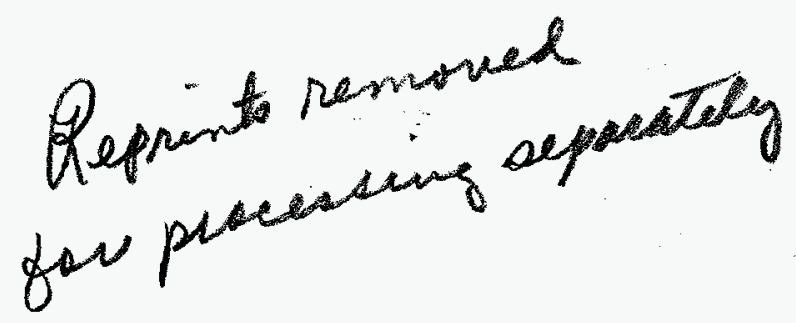

